\title{
The Theory of the Value Orientation and Implementation Path of Social Governance
}

\author{
Zhu Jianding \\ Southwest Forestry University \\ Kunming, China \\ (529147431@qq.com)
}

\begin{abstract}
The key to the transformation of social construction from management to governance is to choose the value orientation according to the transformation. The function of fairness, justice, democracy, equality, rule of law and transparency are very significant undoubtedly during the transformation. The value orientation of regarding individualism as the action rule usually Maximizes individual interests. From the perspective of normative research, this paper analyzes the significance of public rationality to the transformation of social governance. On the basis of summarizing the research results of others, we find the forming conditions of public rationality in social governance. We believe that the value orientation of social governance should be based on the political value of the most basic public rationality as the guide. Therefore, the social atmosphere of tolerance, the appropriate civil wisdom and the platform of cooperative governance construct the basics of the formation of public rationality in social governance.
\end{abstract}

Keywords-social governance, value orientation, public rationalities, path

\section{INTRODUCTION}

Social governance is an important part of national governance system. Since China's reform and opening up, in the course of the construction of social abuses in governance mode is more and more prominent. It creates the situation of big government and small society, and causes the unbalanced relationship between government and society, and discourages the social forces in society construction, which has failed to effectively form the development pattern of the government and society to promote each other. The government's public power often harms the interests of the social, and severely restricts the social main body's ability of governance. And the formation of this pattern and the value orientation of the government to take have a close relationship. Labor in the process of social construction, such as equality, the rule of law, fairness and justice, the good value concept is based on instrumental rationality, individual rationality, department (organization) rationality on the building of which outside watching the cloak of governance, line department, the reality of the individual interests. As a result, the ability of social governance form needs to build on the basis of the public changes, to achieve reunification of the substantial changes and value rationality.

\section{Public Rationality on the SigNIFICANCE OF SOCIAL GOVERNANCE}

Public rationality is the embodiment of the citizen accomplishment and sentiment, is also one of the most important aspects of the civic consciousness. Rational citizen (public) is a common way of thinking and work ability of cooperation, is also a kind of making the rationality into the rationalization process, It is a main process of unity of equality and target of the public. ${ }^{[1]}$ Without public rationality, Justice, equality, democracy and the rule of law cannot be effectively implemented; otherwise, the form of equality, justice and democracy will flood in social governance. Public rationality cultivation and forming process is also the process which the concept of social governance practices.

\section{A. The Public Rationality is a Way to the Transformation of other Social Value Orientation}

Social governance needs a transformation from the government as the single management main body to the government-led, social organizations and citizens to participate in "a main multivariate" governance body, public rationality must be the main value orientation. ${ }^{[2]}$ The reason mainly has: (1) the individual rationality from its own standpoint, often stands for individual interest's departmental (organizational) interest or short-term interests, because maybe it is difficult to judge and choose future state. Driven by this kind of value orientation, main body's consciousness of social construction is personal, rather than public. Social governance needs public awareness under the rule of common governance. The public consciousnesses emphasize the transformation from individual thinking to public rational thinking, namely Schultz of "intersubjectivity" thinking. (2) the management pattern of" one main multivariate "need in power system, the government is reasonable in the process of running the government as a" rightist "subject. Urgently needed to convert the thinking of the government's stance dispel" government driven. Really regarded them as "in role playing the embodiment of public, rather than the government's agent. It need the government and social main body and other actors in the interactive" intersubjectivity "positioning of the government's role and function. (3) social governance goal is the common social goals under the coupling of individual rationality and the governmental rationality. This common goal is public, representing the direction of human society, seeking human welfare and goal of 
all the social main body, so it is a common pursuit of the public good.

\section{B. The Public Reason is the Foundation of other Value Orientation of Social Governance}

In the process of human social development, People pursuit in political equality. Some of the vocabulary reflects the expectation for having heard it many times and hopes for a better society. These values are mainly in fairness, justice, equality and the rule of law, these values are in line with the public's physical and pursuit of good. But in political practice, if individual rationality is the starting point of the fairness, justice, equality and the rule of law, is respect for individual interests of fairness and justice, equality and the rule of law, The value orientation in the social reality that will be distorted, and it will become a mockery of advocating the expansion of individual rights. Under the guidance of the value orientation, the "Marx doctrine" must be a practical activity in the form of formal democracy, the rule of law, the form of equality and so on. Therefore, under the guidance of contemporary Marx, the social governance needs to change the mode of practice management under the guidance of public rationality.

\section{Public Rationality is the Value Orientation of Transformation from Social Construction to Social Governance}

The public rationality needs answer accurately the relationship between the government and society? China's development in a long period of time, the focus of social construction is how to make the government more powerful on this issue. And the idea of "strong government is equal to the big government" and "all powerful government" has been guiding the practice of social construction in our country. In fact, reality that only the government is strong causes the violation and infiltration of private rights. In this process, the development of social interest subject is limited, and it is not effective to form a kind of checks and balances and to promote the government to continue to improve.

Strength disparity in the pattern of governance does not really promote all round development of the society. The key to the transformation of social construction to social governance lies in the formation of the pattern of government and related interests under the guidance of public rationality. The key to the transformation of social construction to social governance is the formation of the government and the relevant subjects under the guidance of public rationality. ${ }^{[3]}$

\section{The Public Rationality In the FORMATION OF SOCIAL GOVERNANCE}

The formation of public rationality is the generation of an ideal implementation and the practice field response; and it Is a dynamic interactive system which in the formation process of the dynamic interaction system government and relevant stakeholders cooperate and govern together. The formation of public rationality in the social governance needs the self consciousness and reflection to the "public" of the government and the relevant stakeholders. In order to achieve interactive development under the balance of power, we should not only think of Historical tradition, cultural tradition and economic development level timely, but also consider comprehensively The power structure of the social factors in the social relationship network from the perspective of Holistic Governance.

\section{A. Formation of Public Rationality in the Practice Field}

The formation of public rationality requires equal mutual trust in social life, and common rules of public recognition. The public rationality is not only the thinking ability of the main body of society, but also the social subject's compliance and acceptance to the common value norm. The formation of public rationality requires such practice field which has a commensurability and Self Justification under letter. Commensurability mainly refers to a set of shared social organizational personality between participants which can bring the common good.

Whether it is under the organization's management and the management of the third sector or enterprise organization management, they in common claims shared a characterization of the public good organization personality, the organization personality requires to dialogue and express their ideas equally in the field of social practice. Even in the case of moral disagreement, the belief in justice and good faith is still to be respected, and the right to respect different voices and expression in their differences should be asserted. The government is no longer the only right advocate in the social governance, under the premise that can Do their own work, to listen to others' expression of the rights, and respect their reasonable existence.

The practical rationality of the public rationality needs to be self - evidence. The legitimacy of this kind of self evidence should be reflected by the development of public affairs. Specifically, if the subject of participation in social governance is divided into government, business, the third sector, there are a variety of government activities relevant stakeholder. in public affairs the legitimacy of the self-evidence have different manifestations. The counterparts of the government and the government are the key components of these subjects. The Legitimacy under the self - Evidence is embodied by effectiveness of public affairs through exertion of public power This effectiveness is not only the realization of the expected goals, but also the effectiveness of the activities of the public affairs and the validity of the results. The legitimacy of the government under the self - evidence may be characterized through the objective of the government, the effectiveness of the process and the results. Why The reason is self evidence, because the people's expectations of the government's behavior is very Obvious. Under the guidance of conscious awareness, the government can show the collective attitude through public behavior. Therefore, the practice field which is formed from public rationality is deeply rooted in the public cultural system, and it involves the most basic moral and value. ${ }^{[4]}$ 


\section{B. The Public Reason Needs to be Formed in the Dynamic Interaction between the Government and the Related Subjects}

It has the meaning of interaction, mutual, inter subjectivity and so on. If we rely solely on the government itself, it is difficult to form the public rationality in the social governance. Conversely, if we rely solely on the subject in the field of society, and without the participation of the government, the public reason is also dangerous. The formation of public reason needs to construct a dynamic interaction system between the government and the related social subjects. The dynamic interaction of the system according to the theory of TR burns the actor system dynamics, composed of the following elements: (1) the interaction rules; (2) the possibility of collective action between the different actors; (3) common interests and orientation between the actors. ${ }^{[5]}$ Therefore, in the process of forming the public reason, it is essential to consider the dynamic interaction between the government and the related subjects. In the process of social governance, through the interactive rule of public reason, it definitely needs the mutual construction between the government and the related subjects. Besides, the power of other subjects should be structured into the interactive rules.

The formation of the interactive rules requires that the government and the related social subjects have equal rights in the exchange process. The equal power here does not mean that the government and other social subjects have same public power, resource advantage and role of the task. It means that the main body can dialogue and interact with the government, there are channels expressing willingness and the opportunity to be concerned about. Only to realize the equal power exchange, the formation of the government and the relevant body interaction rules is impartial, and the interaction rules can reflect government and social forces in the balance of mutual promotion and supervision. Government action or individual action of a social subject can not produce public rationality. Public rationality needs to be formed in the collective action based on the interaction between the government and the related subjects.

Collective action reveals the phenomenon of diversification in social governance. How to produce collective action under the background of subject diversification is a key issue in the development of social governance. The collective action under the multi subject is not a simple linear combination problem, but a complicated proposition in the non-linear relationship. The formation of collective action should not only have a common value appeal, but also need to have a consensus and tolerance. The public rationality needs to respect the interests and values of different actors: the government and related social subjects often have different interests. If only from the perspective of their own agents, individual interests tend to dominate the value, it will also emphasize the maximization of individual interests, the value orientation is individual rationality. The value orientation of public reason needs to be detached from the individual interests to seek common good. The inevitable requirement of government and social subjects show more of the superego components, accept more public moral socialization process, in under the guidance of the "common good" more intense sociality. Obviously, the public reason needs to go beyond the control of individual interests, and it is urgent to cultivate the public morality of each subject of social governance.

\section{The Formation of Public Rationality Requires Reflection and Mutual Consultation.}

The formation of consensus of public reason is a process of mutual consultation of multiple subjects. The subject based on the rationality of position expression for each one airs his own views, presided over the claim. And pay attention to the wording and modification in the expression, to consider this expression can bring the resonance effect. The process of $\mathrm{CO}$ negotiation can be able to eliminate the rational, which is the core of its own, and the consensus is often beyond the position of oneself, and it is reasonable, appropriate or acceptable to other subjects. Therefore, the public reason is often produced in the process of the multi subject joint consultation. In this process, each subject in addition to expressing their own voice, but also need to consider their own voices were accepted and recognized the impact of factors. At the same time, in the process of constantly reflecting on their own behavior, we need to know their own status and consciousness. Of course, there is a certain condition in the negotiation behavior of each subject in the social governance. In Chinese society, the government's voice has been playing an overwhelming role. In the construction of the society, the use of the administrative coercive management method does not give the other subjects the right to equal consultation and opportunity.

Although the petition system to give voice channels and opportunities for ordinary people, but under the leadership of the power of thinking, the petition system has been a strong force of local forces in the event of kidnapping abound. Hearing system in a certain extent give stakeholders the opportunity to express ideas, but in fact, in the design and operation of the system, a good environment for the operation of system is the key to the real implementation of the deliberative democracy. Therefore, public reason of formation for the social governance is a systematic project, also is not an overnight can be formed.

\section{The Formation of Public RATIONALITY In SOCIAL GOVERnANCE}

There is no doubt that the importance of public reason for social governance is beyond question. The social reality of "one main diversity" and "coexistence of various management tools" urgently needs to cultivate and develop the public rationality, and to alleviate the threat of the instrumental rationality and individual rationality to the collective action. In the process of social governance risk is often man-made, unpredictable, only by mobilizing the power of the main body to see the results of joint governance. By the government itself, the government can not effectively deal with this complex problem. 


\section{A. Transformation of Government Thinking, Tolerance to the Objective Existence of the Various Social Subjects}

In the social governance, the formation of public reason needs the innovation of the government itself. Although the government plays a central role in the whole social governance, but "all things are related to the government" mode of thinking has been a strong impact on the social consciousness of the government and related subjects. Several historical events have proved that the government is not omnipotent, and the government will fail. Government's position in social governance can not be shaken: however the government's ability is limited. Therefore, the government needs to a peaceful state of mind, to think of themselves as one of the main body of the social governance, and other subjects in Public Affairs Consultation in the status of equal dialogue, rather than high above. Governments need to put a low profile, in the field which is not good or powerless, the government needs to decisively give up power, so that other social subjects have the opportunity to show the ability and level.

\section{B. Civic Education, Foster Civic Wisdom}

The generation of public reason is the process of the development of the whole social personnel's quality and wisdom. "What kind of citizen groups, there will be what kind of government", this sentence has been a tension between the government and social forces. If the government is too strong, and social forces will be relatively weak. If the government has the tendency of "evil", the citizens powerless to supervise and correct, it will lead to the orders getting worse, and more and more people are being squeezed civil rights. On the contrary, if the people are strong, they can not only supervise the behavior of government, but also urge the government to continuously improve their own and enhance the ability and quality of the government. The formation of this process needs long-term civic education, cultivating citizen wisdom. Citizens can see and reflect on their own behavior, awareness of the consequences of their own behavior, the only way, the formation of a public rationality has a solid foundation of the masses and the masses of the people.

\section{Create a Common Platform for each Subject}

Public rationality is produced in the process of bargaining between multiple subjects. This process finally points to the consensus from the perspective of divergence. To embody the different opinions of different subjects is to respect the rights and abilities of the subjects. Social governance in the social affairs are settled on the social basis, basic situational features if it cannot be perceived by the public power executors, the resulting decision is often divorced from the actual command. Therefore, in the process of social governance, the diversification of the interests of the subject is a reality that can not be ignored, to fully respect the interests of different interests of the main demands; it should be to create a platform for public consultation.

In summary, the value orientation of social governance should be based on the public reason. The public rationality is a kind of value orientation which goes beyond the tool reason, the individual reason and the Department reason and pursues the "common good". This orientation is the relentless pursuit of human development, which is the common happiness of human beings. The formation of public rationality requires a certain condition, and there is a corresponding construction path. It needs to correctly handle the tension between the government and society in the process of social governance.

\section{REFERENCES}

${ }^{11}$ Qian Hong, Mengyu: "to rule of law to foster public rational - and on the realistic significance of the rule of law of the Chinese parties", journal of Zhejiang university (humanities and social science edition), 2013, 43 (5).

${ }^{\text {[2] }}$ The Chinese Marxism and the contemporary drawing board: the Chinese Marxism and the contemporary, higher education press, August 2015), p.

${ }^{[3]}$ Qian Hong, Mengyu: "to rule of law to foster public rational - and on the realistic significance of the rule of law of the Chinese parties", journal of Zhejiang university (humanities and social science edition), 2013, 43 (5).

${ }^{[4]}$ Zhang Yu: "public reason: the conditions of the public policy participation", "social science research, 2011, 2.

${ }^{[5]}$ [Sweden] Tom R Burn, "the view of structuralism: economic and social change", social sciences academic press, September 2000, pp. 127-126. 